\title{
Prevention and Control Strategies to Counter Dengue Virus Infection
}

\author{
Irfan A. Rather ${ }^{1}$, Hilal A. Parray ${ }^{2}$, Jameel B. Lone ${ }^{2}$, Woon K. Paek ${ }^{3}$, Jeongheui Lim ${ }^{3 *}$, \\ Vivek K. Bajpai ${ }^{1 *}$ and Yong-Ha Park ${ }^{1 *}$
}

${ }^{1}$ Department of Applied Microbiology and Biotechnology, School of Biotechnology, Yeungnam University, Gyeongsan, South Korea, ${ }^{2}$ Department of Biotechnology, Daegu University, Gyungsan, South Korea, ${ }^{3}$ National Science Museum, Ministry of Science, ICT and Future Planning, Daejeon, South Korea

\section{OPEN ACCESS}

Edited by:

Gong Cheng,

Tsinghua University, China

Reviewed by:

Tonya Michelle Colpitts,

University of South Carolina,

United States

Long Yang,

New York Medical College,

United States

*Correspondence:

Jeongheui Lim

jeongheuilim@gmail.com;

Vivek K. Bajpai

vbajpai04@yahoo.com;

Yong-Ha Park

peter@ynu.ac.kr

Received: 10 May 2017

Accepted: 10 July 2017

Published: 25 July 2017

Citation:

Rather IA, Parray HA, Lone JB,

Paek WK, Lim J, Bajpai VK and

Park Y-H (2017) Prevention and Control Strategies to Counter Dengue

Virus Infection.

Front. Cell. Infect. Microbiol. 7:336. doi: 10.3389/fcimb.2017.00336
Dengue is currently the highest and rapidly spreading vector-borne viral disease, which can lead to mortality in its severe form. The globally endemic dengue poses as a public health and economic challenge that has been attempted to suppress though application of various prevention and control techniques. Therefore, broad spectrum techniques, that are efficient, cost-effective, and environmentally sustainable, are proposed and practiced in dengue-endemic regions. The development of vaccines and immunotherapies have introduced a new dimension for effective dengue control and prevention. Thus, the present study focuses on the preventive and control strategies that are currently employed to counter dengue. While traditional control strategies bring temporary sustainability alone, implementation of novel biotechnological interventions, such as sterile insect technique, paratransgenesis, and production of genetically modified vectors, has improved the efficacy of the traditional strategies. Although a large-scale vector control strategy can be limited, innovative vaccine candidates have provided evidence for promising dengue prevention measures. The use of tetravalent dengue vaccine (CYD-TDV) has been the most effective so far in treating dengue infections. Nonetheless, challenges and limitation hinder the progress of developing integrated intervention methods and vaccines; while the improvement in the latest techniques and vaccine formulation continues, one can hope for a future without the threat of dengue virus.

\section{Keywords: dengue virus, infection, vaccine, disease, fever}

\section{INTRODUCTION}

Dengue is a mosquito-borne viral infection (Simmons et al., 2012), which has affected almost 2.5 billion people around the globe (Koh et al., 2008). It is transmitted by vector species Aedes aegypti and poses a global threat to humans due to its high adaptability to urban communities (Araújo et al., 2015). In 2012, WHO reported that dengue outbreaks place a large burden on communities, healthcare systems, and economies in most tropical countries worldwide. According to WHO, Asia, Americas, Africa, and the Mediterranean regions are affected by the emerging and prevailing DENV (WHO, 2012).

Recently, Bhatt et al., estimated about 390 million DENV infections occurring each year, of which 96 million were seemingly evident (Bhatt et al., 2013). The DENV infection starts with mild fever, and further leads to many other consequences (Figure 1). However, preventive strategies for DENV have been developed in the form of vector control, including chemical, biological, and 
physical controls. Apart from general control strategies, development of vaccines have offered effective prevention and control of this disease (DeRoeck et al., 2003).

Similarly, the following study aims to discuss the prevention and control strategies to counter DENV, including the development of immunotherapies and vaccines. It also examines the challenges confronted in the effective implementation of these strategies in light of peer reviewed literature, and draws a conclusion of the research.

\section{Prevention and Control Strategies}

The prevention and control methods are divided into three categories, which have been discussed accordingly.

\section{Physical Control GIS Mapping of Dengue Foci}

Among the advanced techniques used for location of DENV, GIS mapping has been efficient in locating dengue concentrations. By locating dengue seri-positive cases within the study area, dengue transmission can be prevented by locating dengue foci, and then treating them with diverse preventive strategies (Gandhi et al., 2017). Kittayapong et al., showed that GIS mapping not only allowed better surveillance and community-based intervention programs for suppressing dengue; it also determined the rate of successful control in the mapped areas. In their study, surveillance of the mapped dengue foci determined the major breeding sites of $A$. egypti mosquitoes to be water containers and bath basins (Kittayapong et al., 2008).

\section{Focused and Effective Surveillance}

Surveillance provides fundamental information on the assessment of risk, outbreak reaction, program evaluation and guidance, as well as delivers timely responses to prevent and control dengue (Wilder-Smith et al., 2012). Surveillance enables the understanding of spatiotemporal distribution of dengue cases, and provides entomological and epidemiological links for better planning (WHO, 2012; Scarpino et al., 2017). On the other hand, these programs are not focused on the elimination of dengue vector (Abbas et al., 2014). The eruption of dengue in Singapore, after decades of surveillance, indicated unsustainable vector control measures and ineffective surveillance (Ooi et al., 2006) in 2005 (Koh et al., 2008). An effective surveillance system aiming at vector identification (Gómez-Dantés and Willoquet, 2009) and eradication (Abbas et al., 2014), providing the underlying information regarding vector concentration and its breeding, will prove beneficial in controlling vector species.

\section{Determination of Oviposition Sites}

As determined by Morrison et al., Aedes aegypti females lay eggs above the water in containers or jars and so on for their survival improvement (Morrison et al., 2004). To detect and reduce the population density of dengue vectors, it is necessary to determine the behavioral pattern of vectors. Wong et al., studied the oviposition pattern of $A$. aegypti and reported that strong intra-specie affinity may be an indication of targeting vector specie. Moreover, once the oviposition sites have been determined, introduction of strategies that eliminate mosquito population at a later developmental stage will increase the efficacy of control strategies (Wong et al., 2011). Recently, introducing oviposition-based innovative techniques have shown promising results in intensifying control of vector species (Johnson et al., 2017).

\section{Community-Based Control Programs}

Community-based control programs are developed with the aim to educate the community about the measures for the extermination of mosquito breeding sites. People in a community are divided into various groups depending upon their level of education and understanding (Abbas et al., 2014). The significance of community-based programs for elimination of dengue mosquitoes in Kerala district (George et al., 2017), Mexico (Tapia-Conyer et al., 2012), and Cuba (Vanlerberghe et al., 2010) has been proven in the form of elevated awareness among the communities. Through community involvement, a variety of techniques can be integrated for maximum control of vector population (Heintze et al., 2007; Pérez-Guerra et al., 2009; Shriram et al., 2009), such as, the combination of communitybased program and chemical control of $A$. aegypti have yielded significant results in Cuba (Baly et al., 2007).

\section{Education of Prevention Strategies}

It has been noted that the success of community-based strategies depends upon the knowledge, education, and behavior of the people, and strategies involved (Nam et al., 2005). Education serves as a basis for an ability of an individual to identify and deal with vector habitats, and use preventive measures. Madeira et al., emphasized that distribution of information brings awareness in order to control dengue, and provides necessary measures for the destruction of vector habitats (Madeira et al., 2002). A recent study in Thailand showed that education of prevention strategies through media also played a vital role in developing awareness (Boonchutima et al., 2017).

\section{Biological Control}

\section{Paratransgenesis and Use of Wolbachia}

Nowadays, genetic control of $A$. aegypti has risen as a set of promising techniques, among which paratransgenesis is the popular method (Araújo et al., 2015; Ogaugwu and Durvasula, 2017). This approach utilizes genetically-modified symbiotic bacteria that are reintroduced in the vector to colonize the vector population, hence limiting the transmission of disease (Araújo et al., 2015; Wilke and Marrelli, 2015). These genetically modified bacteria cause harmful effects in the host body, dysregulate its sexual cycle, decrease the host competence and interfere with the developmental processes of the vector species, thereby suppressing the vector population (Wilke and Marrelli, 2015). As reported in the study by Jeffery et al., the most effective bacterial agents used is Wolbachia (Jeffery et al., 2009; Saldaña et al., 2017), which is a reproductive parasite interfering with the cellular and reproductive mechanisms of the vector species (Araújo et al., 2015; Kamtchum-Tatuene et al., 2016). 


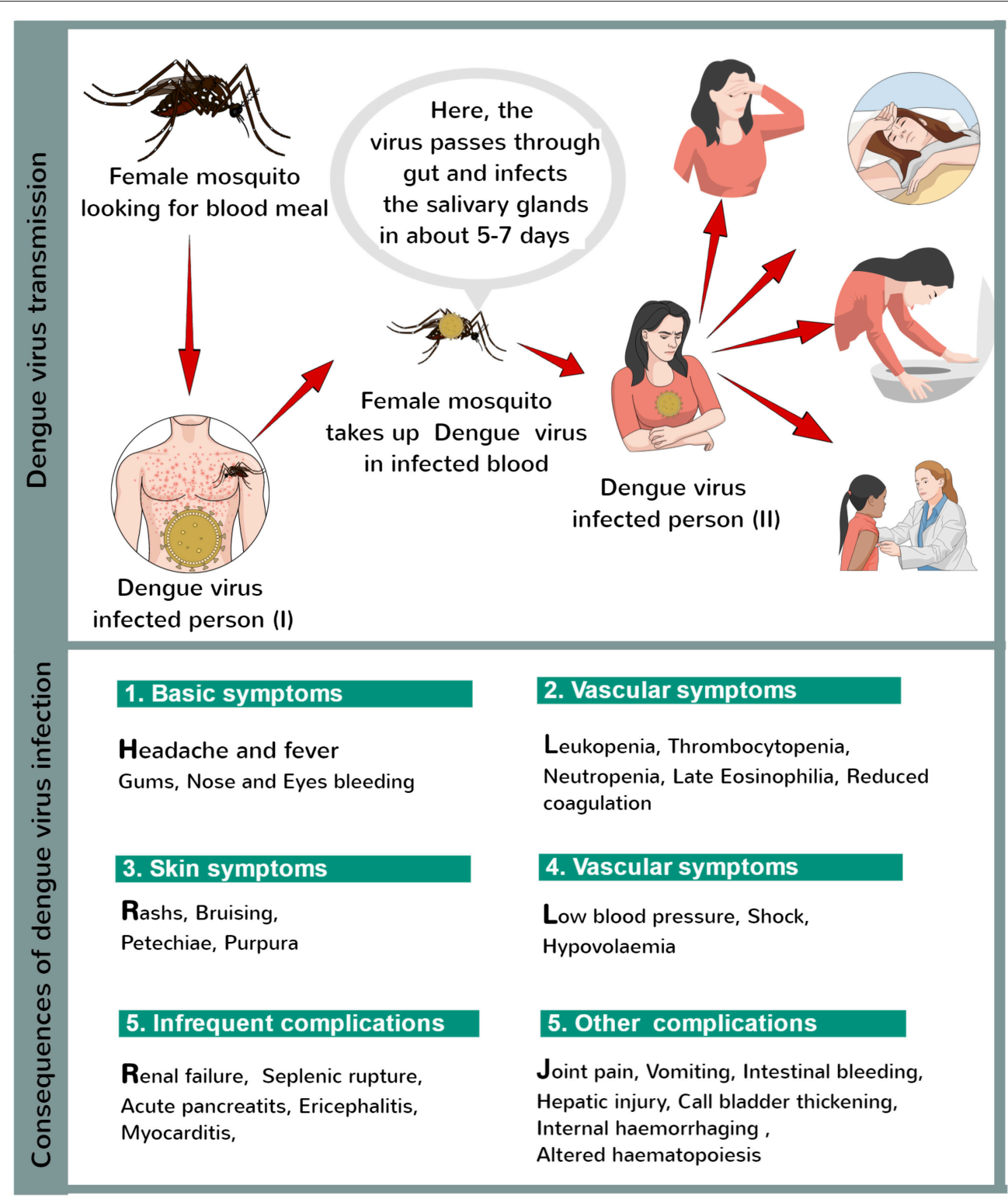

FIGURE 1 | Dengue virus infection.

\section{Vector Specie Genetic Modification}

The genetic methods for the control of A. aegypti aim at suppressing the population and its replacement or transformation. Therefore, the aim is designed to provide an alternate that could be accounted for providing an effector gene for reduction and inhibition of disease transmission (ReisCastro, 2012; Carvalho et al., 2014; Jupatanakul et al., 2017). The field release of genetically modified mosquito species in Brazil showed an $85 \%$ decline in A. aegypti population (Pan American Health Organization, 2014), indicating that genetically modified vector species are innovative and feasible methods used for blocking the transmission of mosquito-borne diseases (Fraser, 2012; Favia, 2015).

\section{Use of Sterile Insect Technique (SIT)}

As the name indicates, SIT refers to the release of laboratorysterilized male vectors in the target population. Once released, these male mosquitoes help in suppressing the fecundity rate in female mosquitoes and, consequently control the vector density in urban environments (Dumont and Chiroleu, 2010; Yakob et al., 2017) and transmission of vector-borne diseases (Alphey et al., 2010). According to Oliva et al., SIT is a promising strategy that helps in prevention and control of mosquito-borne diseases. After examining the irradiation effect on sterile male, they stated that sterile males were potential competitors and can help suppress the number of offsprings (Oliva et al., 2012). 


\section{Use of Larvivorous Fish and Crustacean}

Since the larvae of dengue vectors reside in open water bodies, use of larvivorous fish, such as Poecilia reticulate (Seng et al., 2008) and Mesocyclops formosanus (Kalimuthu et al., 2017) comes as a cost-effective, eco-friendly, and innovate strategy in controlling the population of A. aegypti (Abbas et al., 2014; Han et al., 2015; Warbanski et al., 2017). A successful study in Cambodia was carried out to evaluate the efficacy of introducing larvivorous guppy fish (Poecilia reticulata) into heavily infested water containers. It showed that the guppy fish in test houses reduced vector larval population by $79 \%$ as compared to control houses, thus indicating successful implementation of this strategy (Seng et al., 2008).

\section{Chemical Control}

\section{Use of Insecticides and Plant Derivatives}

The chemical compounds, called insecticides, have been utilized for mosquito control for many decades. These insecticides became the most commonly used integrated strategy; nevertheless, the continuous use developed resistance in the target vector population, and can induce negative impacts on the environment (Araújo et al., 2015). To counter the effects of these compounds, researchers developed alternative control method i.e., introduction of plant-based insecticides that can sustain and induce less toxicity in environment than synthetic insecticides (Ghosh et al., 2012). These plant-based insecticides can be developed from different plant parts (leaves, stem, roots) and/or herbal extracts, such as, Cipadessa baccifera (Ramkumar et al., 2015), Callistemon rigidus (Pierre et al., 2014), Erythrina indica, and Asparagus racemosus (Govindarajan and Sivakumar, 2015). Furthermore, these plant derivatives are not only limited to produce insecticides; however, they have also proved their efficiency as potential repellents against $A$. aegypti (Araújo et al., 2015; Govindarajan and Sivakumar, 2015).

\section{Use of Insect Growth Regulators (IGRs)}

Among other known chemical compounds, insect growth regulators (IGRs) are used for hindering the growth and development in insects. During early stages of development, IGRs induce changes that kills the insect before becoming an adult. There are number of IGRs such as, diflubenzuron, endotoxins, and methoprene that have been used to counter viral infections spread by A. aegypti (Abbas et al., 2014). According to Lau et al., field population of vector species develops resistance to certain IGRs; and in their study, they found that cyromazine showed effective results in attenuating larval population indices of $A$. aegypti (Lau et al., 2015).

\section{Use of Pheromones as "Attract-and-Kill" Approach}

The practical application of pheromones as a part of integrated pest management (IPM) has been well-documented in various fields. In a recent integrated approach using pheromones, also termed attracticides, and IGRs, Nagpal et al., demonstrated the prevention of developmental stages from eggs to adults (Nagpal et al., 2015). In this study, larvae in test containers were found in a greater number than controls containers, which indicated that using attracticides hampers the progression of adulthood in A. aegypti and is effective in field conditions (Nagpal et al., 2015). Another study developed an uncomplicated "lethal lure control" based on attract-and-kill strategy and found that the pheromone (caproic acid)-insecticide (temephos) combination not only attracted mosquitoes, but also restricted hatching of eggs and killed the larvae, thus elaborating its significance (Ong and Jaal, 2015).

\section{Development of Immunotherapies and Vaccines}

Although no specific vaccine for dengue has been licensed at commercial scale, several candidates have been undergoing a developmental phase. Some of these are discussed below:

\section{Live, Attenuated Dengue Vaccines}

Among the vaccines having been improved, the development of live, attenuated vaccines, known as ChemariVax-Dengue (CYD)-based bivalent and tetravalent vaccines (CYD-TDV), have shown protection against DENV in a trial conducted in Mexico (Dayan et al., 2014). The study determined that the group receiving bivalent vaccine showed an immune response against CYD serotype 3, while the immune response rates of other group receiving first injection of CYD-TDV were generally higher and well-tolerated (Dayan et al., 2014). Evidences from randomized, controlled studies have emphasized the importance of tetravalent CYD vaccine in Asian (Capeding et al., 2014), Thai (Sabchareon et al., 2012), and Latin American (Villar et al., 2015) children along with adults in Singapore (Sin Leo et al., 2012), suggesting its potential in providing protection against various CYD serotypes. However, studies also suggested the lower risk of CYD in CYD-TDV vaccinated children aged 2-16 years than the unvaccinated control group (Hadinegoro et al., 2015), neutralization of antibody response to dengue serotypes, and safe profile of CYD-TDV (Qiao et al., 2011; Villar et al., 2013). The available candidates for dengue vaccine are listed in Table 1.

Besides live and/or attenuated vaccines, inactivated and non-replicating vaccines have also been used. The developing non-replicating vaccine approaches focus on recombinant DENV antigens, inactivated viruses, and use of non-replicating transmission agents produced specifically to extract DENV antigens in vivo. Using inactivated vaccines also reduce the risk of infection by conferring resistance. Also, subunit vaccines and genetic vaccination have been developed to respond to the inactivated viruses (Swaminathan and Khanna, 2010).

Recent outbreak of Zika virus (ZIKV) epidemics has raised a growing concern in many parts of the world. However, several viral diseases have been controlled using vaccination strategies. Nevertheless, for majority of arthropod transmitted viral diseases, there is no specific vaccine yet. Therefore, exploring potential transmission blocking vaccines (TBV) could halt the viral infection to humans, and could be applied to most of the arboviruses, including chikungunya, DENV, and ZIKV.

\section{Development of Dengue Human Infection Model}

In order to develop the understanding of DENV pathogenesis and effective dengue countermeasures, the evolution of the 
TABLE 1 | Current Vaccine Candidates for Dengue Prevention (Source:Sandrasegaran, 2016).

\begin{tabular}{|c|c|c|c|}
\hline Vaccine type & Developer & Process & Progress \\
\hline \multirow[t]{3}{*}{$\begin{array}{l}\text { Live, attenuated chimeric } \\
\text { (recombinant) }\end{array}$} & Acambis/Sanofi Pasteur & $\begin{array}{l}\text { Insertion of genes coding for DENV structural } \\
\text { proteins into a yellow fever virus (17D) backbone. }\end{array}$ & $\begin{array}{l}\text { Phase III tetravalent-leading } \\
\text { candidate }\end{array}$ \\
\hline & Centre for Disease Control (CDC)/Inviragen & $\begin{array}{l}\text { Insertion of serotype genes into serotype II (DENV2- } \\
\text { PDK53) DNA backbone. }\end{array}$ & Phase II monovalent \\
\hline & $\begin{array}{l}\text { National Institutes of Health } \\
(\mathrm{NIH}) / \text { University of Maryland }\end{array}$ & $\begin{array}{l}\text { Insertion of serotype II and III genes into safer, more } \\
\text { immunogenic serotype I and IV DNA backbone. Live } \\
\text { attenuated DENV Delta-30 mutation }\end{array}$ & Phase I tetravalent \\
\hline \multirow[t]{2}{*}{ Live, traditionally attenuated } & $\begin{array}{l}\text { Walter-Reed Army Institute of Research } \\
\text { (WRAIR)/GlaxoSmithKline (GSK) }\end{array}$ & $\begin{array}{l}\text { Attenuation achieved by growing the virus in } \\
\text { cultured cells and selecting strains }\end{array}$ & $\begin{array}{l}\text { Phase II tetravalent; technical } \\
\text { issues }\end{array}$ \\
\hline & Mahidol Institute/Sanofi Pasteur & & Phase II tetravalent \\
\hline Inactivated & GSK & Viruses cultured and killed & Phase I tetravalent \\
\hline Subunit & Hawaii Biotech & $\begin{array}{l}\text { Viral immunogenic envelope is combined with viral } \\
\text { non-structural protein antigens to produce } \\
\text { recombinant } 80 \% \text { E subunit vaccine }\end{array}$ & Phase I tetravalent \\
\hline DNA & WRAIR & $\begin{array}{l}\text { Dengue prM-E DNA vaccine incorporating } \\
\text { membrane and envelope genes into a plasmid } \\
\text { vector }\end{array}$ & Phase I monovalent \\
\hline
\end{tabular}

dengue human infection model (DHIM) is also deemed necessary. Developing a DHIM requires a thorough examination of measures to reduce risks to participants and guidelines for clinical management. Moreover, DHIM serves as a promising research tool, which enables the understanding of pathways for vaccine development, examines the immunological pathogenesis, exploits protection by immune associates, supports the evolution of vaccine clinical development, and would put into effect the efforts for the development of effective vaccines (Thomas, 2013). In line with the same notion, murine infection models have also shown to be effective in examining DENV pathogenesis and evaluation of vaccine candidates and antiviral drugs (Sarathy et al., 2015).

\section{Introducing Balance in Immunity and Reactogenicity}

The two way relationship between immunity and reactigenicity has long been discussed with regards to DENV infection. It has been noticed that elevated reactogenicity may lead to a better immune response in some vaccine candidates; nonetheless, severe outcomes may be caused in others. Similarly, lower reactogenicity may result in deficient immune response (Perng et al., 2011). An ideal CYD-TVD vaccine for DENV should be able to minimize the harmful effects along with providing host responses that enhance immune protection and immune evasion. To maintain the proper balance between reactogenicity and immunity, the vital components in the CYD-TDV vaccine play an important role (Perng et al., 2011; Kirkpatrick et al., 2015), which remains a crucial yet biggest task to the vaccine development strategies.

\section{Mitigation of the Risk of Autoimmunity}

During current vaccine development strategies, the role of crossreactive antibodies as mediators of DENV infection has not been the center of attention among the vaccine developers (Nikin-Beers and Ciupe, 2015). Thus, the cross-reactivity of these antibodies has not been considered as a part of the efficacy evaluation index in the clinical trials of CYD-TDV vaccines. However, the details of the protein sequencing in viral antigens eliciting autoimmunity have been well-documented (Perng et al., 2011). Moreover, the significant side effects can be lessened and safety profile of dengue vaccines can be enhanced by applying a strategy, which requires modification of viral genomes genetic code sequence and alteration of these determinants in these altered viral strains (Cheng et al., 2009; Perng et al., 2011).

\section{Enhancement of the Efficacy of Antibody-Producing Plasma Cells}

During vaccine development program, the significance of antibody-producing B cells is highly observed. Of the main strategies proposed to improve vaccine potential is the high survivability of plasma or memory B cells (Nothelfer et al., 2015). Furthermore, it has been determined that cysteine-rich interdomain region $1 \alpha(\mathrm{CIDR} 1 \alpha)$ of the $P$. falciparum can defend and save plasma cells from death. Hence, integrating CIDR $1 \alpha$ as an additional component with live and/or attenuated dengue vaccines can improve the survivability and functional potential of the plasma cells (Perng et al., 2011).

\section{Synthetic Nucleic Acid Antibody Immunotherapy}

Since none of the current vaccines could provide a balanced protection against DENV, Flingai et al., reported that production of single intramuscular engineered DNA plasmids with human antiviral neutralizing antibodies (nAbs) protected murine models against antibody-modified DENV (Flingai et al., 2015). While the currently used vaccines produce traditional antibodies, the authors emphasized that plasmid-encoded LALA antibodies that defend against DENV and antibody-dependent enhancement (ADE)-induced disease can act as an alternative or become an incentive for traditional vaccine strategies. In fact, this synthetic nucleic acid immunotherapy can also be utilized for traveling 
population to increase protection against viral infections and reduce the dengue epidemic (Flingai et al., 2015).

\section{Challenges and Limitations to Dengue Prevention Strategies}

Just as new strategies and vaccines are devised for prevention and control of DENV, there is always a gap left in the form of challenges and limitations for perfect implementation of such strategies (Achee et al., 2015). Since prevention and control strategies to counter dengue have not shown satisfactory results in reducing disease transmission, the utilization of vaccines as cost-effective and potential resistance has become the main priority to restore public health. However, the complicated immunopathology of dengue has perplexed the development of vaccines. These vaccines also confront various challenges, such as unavailability of suitable models for disease and the want for eligible markers of immunity protection (Ghosh and Dar, 2015).

\section{CONCLUSION}

As the pandemic outbreak of DENV continues to prevail in today's world, the development of safe, cost-effective,

\section{REFERENCES}

Abbas, A., Abbas, R. Z., Khan, J. A., Iqbal, Z., Bhatti, M. M. H., Sindhu, Z. U. D., et al. (2014). Integrated strategies for the control and prevention of dengue vectors with particular reference to Aedes aegypti. Pak. Vet. J. 34, 1-10. doi: 10.1097/QCO.0b013e3283638104

Achee, N. L., Gould, F., Perkins, T. A., Reiner, R. C., Morrison, A. C., Ritchie, S. A., et al. (2015). A critical assessment of vector control for dengue prevention. PLoS Negl. Trop. Dis. 9:e0003655. doi: 10.1371/journal.pntd.0003655

Alphey, L., Benedict, M., Bellini, R., Clark, G. G., Dame, D. A., Service, M. W., et al. (2010). Sterile-insect methods for control of mosquito-borne diseases: an analysis. Vector Borne Zoonotic Dis. 10, 295-311. doi: 10.1089/vbz.200 9.0014

Araújo, H. R. C., Carvalho, D. O., Ioshino, R. S., Costa-da-Silva, A. L., and Capurro, M. L. (2015). Aedes aegypti control strategies in Brazil: incorporation of new technologies to overcome the persistence of dengue epidemics. Insects 6, 576-594. doi: 10.3390/insects6020576

Baly, A., Toledo, M. E., Boelaert, M., Reyes, A., Vanlerberghe, V., Ceballos, E., et al. (2007). Cost effectiveness of Aedes aegypti control programmes: participatory versus vertical. Trans. R. Soc. Trop. Med. Hyg. 101, 578-586. doi: 10.1016/j.trstmh.2007.01.002

Bhatt, S., Gething, P. W., Brady, O. J., Messina, J. P., Farlow, A. W., Moyes, C. L., et al. (2013). The global distribution and burden of dengue. Nature 496, 504-507. doi: 10.1038/nature12060

Boonchutima, S., Kachentawa, K., Limpavithayakul, M., and Prachansri, A. (2017). Longitudinal study of Thai people media exposure, knowledge, and behavior on dengue fever prevention and control. J. Infect. Public Health S1876-0341, 30051-30055. doi: 10.1016/j.jiph.2017.01.016

Capeding, M. R., Tran, N. H., Hadinegoro, S. R. S., Ismail, H. I. H. M., Chotpitayasunondh, T., Chua, M. N., et al. (2014). Clinical efficacy and safety of a novel tetravalent dengue vaccine in healthy children in Asia: a phase 3, randomised, observer-masked, placebo-controlled trial. Lancet 384, 1358-1365. doi: 10.1016/S0140-6736(14)61060-6

Carvalho, D. O., Costa-da-Silva, A. L., Lees, R. S., and Capurro, M. L. (2014). Two step male release strategy using transgenic mosquito lines to control transmission of vector-borne diseases. Acta Trop. 132, 1-8. doi: 10.1016/j.actatropica.2013.09.023 and potential preventive and control measures, including development of new and improved vaccines, evidently promise the reduction of dengue viral infection. As the strategies grow and are used in an integrated manner with other methods, advanced combinations have also predicted attenuation of vector population. Among the vaccines developed, the approbation of recombinant, live and attenuated tetravalent dengue vaccine has proved safe and tolerable, as well as protective against dengue. With more research and experimentation of novel methods and techniques, the future could enjoy better control with protective immunity to DENV.

\section{AUTHOR CONTRIBUTIONS}

IR wrote the paper and designed figure; HP, JBL, and WP. collected the literature; JL, VB, and YP. designed, analyzed approved the paper.

\section{ACKNOWLEDGMENTS}

This work was supported by National Research Foundation of Korea (2013M3A9A504705 and 2017M3A9A5048999).

Cheng, H.-J., Lin, C.-F., Lei, H.-Y., Liu, H.-S., Yeh, T.-M., Luo, Y.-H., et al. (2009). Proteomic analysis of endothelial cell autoantigens recognized by antidengue virus nonstructural protein 1 antibodies. Exp. Biol. Med. 234, 63-73. doi: 10.3181/0805-RM-147

Dayan, G. H., Galán-Herrera, J. F., Forrat, R., Zambrano, B., Bouckenooghe, A., Harenberg, A., et al. (2014). Assessment of bivalent and tetravalent dengue vaccine formulations in flavivirus-naive adults in Mexico. Hum. Vaccin. Immunother. 10, 2853-2863. doi: 10.4161/21645515.2014.972131

DeRoeck, D., Deen, J., and Clemens, J. (2003). Policymakers' views on dengue fever/dengue haemorrhagic fever and the need for dengue vaccines in four southeast Asian countries. Vaccine 22, 121-129. doi: 10.1016/S0264-410X(03)00533-4

Dumont, Y., and Chiroleu, F. (2010). Vector control for the Chikungunya disease. Math. Biosci. Eng. 7, 313-345. doi: 10.3934/mbe.2010.7.313

Favia, G. (2015). Engineered mosquitoes to fight mosquito borne diseases: not a merely technical issue. Bioeng. Bugs 6, 5-7. doi: 10.4161/21655979.2014.988556

Flingai, S., Plummer, E. M., Patel, A., Shresta, S., Mendoza, J. M., Broderick, K. E., et al. (2015). Protection against dengue disease by synthetic nucleic acid antibody prophylaxis/immunotherapy. Sci. Rep. 5, 1-9. doi: 10.1038/srep12616

Fraser, M. J. (2012). Insect transgenesis: current applications and future prospects. Annu. Rev. Entomol. 57, 267-289. doi: 10.1146/annurev.ento.54.110807.090545

Gandhi, G., Chapla, J., Reddya Naik, B., and Gujju Gandhi, C. (2017). Data mapping of vector borne disease with geographical information system \& global position system technology: in tribal areas Khammam District, Telangana State. Int. J. Mosq. Res. 39, 39-43.

George, L. S., Paul, N., and Leelamoni, K. (2017). Community based interventional study on dengue awareness and vector control in a rural population in Ernakulam, Kerala. Int. J. Commun. Med. Public Health 4, 962-967. doi: 10.18203/2394-6040.ijcmph20170984

Ghosh, A., and Dar, L. (2015). Dengue vaccines: challenges, development, current status and prospects. Indian J. Med. Microbiol. 33, 3-15. doi: $10.4103 / 0255-0857.148369$

Ghosh, A., Chowdhury, N., and Chandra, G. (2012). Plant extracts as potential mosquito larvicides. Indian J. Med. Res. 135, 581-598.

Gómez-Dantés, H., and Willoquet, J. R. (2009). Dengue in the Americas: challenges for prevention and control. Cad. Saúde Pública 25, S19-S31. doi: 10.1590/S0102-311X2009001300003 
Govindarajan, M., and Sivakumar, R. (2015). Laboratory evaluation of Indian medicinal plants as repellents against malaria, dengue, and filariasis vector mosquitoes. Parasitol. Res. 114, 601-612. doi: 10.1007/s00436-014-4222-0

Hadinegoro, S. R., Arredondo-García, J. L., Capeding, M. R., Deseda, C., Chotpitayasunondh, T., Dietze, R., et al. (2015). Efficacy and long-term safety of a dengue vaccine in regions of endemic disease. N. Engl. J. Med. 373, 1195-1206. doi: 10.1056/NEJMoa1506223

Han, W., Lazaro, A., McCall, P., and George, L. (2015). Efficacy and community effectiveness of larvivorous fish for dengue vector control. Trop.Med. Int. Health 20, 1239-1256. doi: 10.1111/tmi.12538

Heintze, C., Garrido, M. V., and Kroeger, A. (2007). What do communitybased dengue control programmes achieve? A systematic review of published evaluations. Trans. R. Soc. Trop. Med. Hyg. 101, 317-325. doi: 10.1016/j.trstmh.2006.08.007

Jeffery, J. A. L., Thi Yen, N., Nam, V. S., Nghia, L. T., Hoffmann, A. A., Kay, B. H., et al. (2009). Characterizing the Aedes aegypti population in a vietnamese village in preparation for a wolbachia-based mosquito control strategy to eliminate dengue. PLoS Negl. Trop. Dis. 3:e552. doi: 10.1371/journal.pntd.0000552

Johnson, B., Ritchie, S., and Fonseca, D. (2017). The state of the art of lethal oviposition trap-based mass interventions for arboviral control. Insects 8:5. doi: 10.3390/insects 8010005

Jupatanakul, N., Sim, S., Angleró-Rodríguez, Y. I., Souza-Neto, J., Das, S., Poti, K. E., et al. (2017). Engineered Aedes aegypti JAK/STAT pathwaymediated immunity to dengue virus. PLoS Negl. Trop. Dis. 11:e0005187. doi: 10.1371/journal.pntd.0005187

Kalimuthu, K., Panneerselvam, C., Chou, C., Tseng, L.-C., Murugan, K., Tsai, K.-H., et al. (2017). Control of dengue and Zika virus vector Aedes aegypti using the predatory copepod Megacyclops formosanus: synergy with Hedychium coronarium- synthesized silver nanoparticles and related histological changes in targeted mosquitoes. Process Safety Environ. Protect. 109, 82-96. doi: 10.1016/j.psep.2017.03.027

Kamtchum-Tatuene, J., Makepeace, B. L., Benjamin, L., Baylis, M., and Solomon, T. (2016). The potential role of Wolbachia in controlling the transmission of emerging human arboviral infections. Curr. Opin. Infect. Dis. 30, 108-116. doi: $10.1097 /$ qco.0000000000000342

Kirkpatrick, B. D., Durbin, A. P., Pierce, K. K., Carmolli, M. P., Tibery, C. M., Grier, P. L., et al. (2015). Robust and balanced immune responses to all 4 dengue virus serotypes following administration of a single dose of a live attenuated tetravalent dengue vaccine to healthy, flavivirus-naive adults. J. Infect. Dis. 212, 702-710. doi: 10.1093/infdis/jiv082

Kittayapong, P., Yoksan, S., Chansang, U., Chansang, C., and Bhumiratana, A. (2008). Suppression of dengue transmission by application of integrated vector control strategies at sero-positive GIS-based foci. Am. J. Trop. Med. Hyg. 78, $70-76$.

Koh, B. K. W., Lee, C. N., Kita, Y., Choon, S. T., Li, W. A., Kit, Y. W., et al. (2008). The 2005 dengue epidemic in Singapore: epidemiology, prevention and control. Ann. Acad. Med. Singapore 37, 538-545.

Lau, K. W., Chen, C. D., Lee, H. L., Norma-Rashid, Y., and Sofian-Azirun, M. (2015). Evaluation of insect growth regulators against field-collected Aedes aegypti and Aedes albopictus (Diptera: Culicidae) from Malaysia. J. Med. Entomol. 52, 199-206. doi: 10.1093/jme/tju019

Madeira, N. G., Macharelli, C. A., Pedras, J. F., and Delfino, M. C. N. (2002). Education in primary school as a strategy to control dengue. Rev. Soc. Bras. Med. Trop. 35, 221-226. doi: 10.1590/S0037-86822002000300004

Morrison, A. C., Gray, K., Getis, A., Astete, H., Sihuincha, M., Focks, D., et al. (2004). Temporal and geographic patterns of Aedes aegypti (Diptera: Culicidae) production in Iquitos, Peru. J. Med. Entomol. 41, 1123-1142. doi: 10.1603/0022-2585-41.6.1123

Nagpal, B. N., Ghosh, S. K., Eapen, A., Srivastava, A., Sharma, M. C., Singh, V. P., et al. (2015). Control of Aedes aegypti and Ae. albopictus, the vectors of dengue and chikungunya, by using pheromone $\mathrm{C} 21$ with an insect growth regulator: results of multicentric trials from 2007-12 in India. J. Vector Borne Dis. 52, 224-231.

Nam, V. S., Yen, N. T., Phong, T. V., Ninh, T. U., Mai, L. Q., Lo, L. V., et al. (2005). Elimination of dengue by community programs using Mesocyclops (copepoda) against Aedes aegypti in central Vietnam. Am. J. Trop. Med. Hyg. 72, 67-73.

Nikin-Beers, R., and Ciupe, S. M. (2015). The role of antibody in enhancing dengue virus infection. Math. Biosci. 263, 83-92. doi: 10.1016/j.mbs.2015.02.004
Nothelfer, K., Sansonetti, P. J., and Phalipon, A. (2015). Pathogen manipulation of B cells: the best defence is a good offence. Nat. Rev. Microbiol. 13, 173-184. doi: 10.1038/nrmicro3415

Ogaugwu, C. E., and Durvasula, R. V. (2017). "Developing the arsenal against pest and vector dipterans: inputs of transgenic and paratransgenic biotechnologies," in Biological Control of Pest and Vector Insects, ed V. D. C. Shields (Rijeka: InTech). doi: 10.5772/66440

Oliva, C. F., Jacquet, M., Gilles, J., Lemperiere, G., Maquart, P. O., Quilici, S., et al. (2012). The sterile insect technique for controlling populations of Aedes albopictus (Diptera: Culicidae) on Reunion Island: mating vigour of sterilized males. PLOS ONE 7:49414. doi: 10.1371/journal.pone.0049414

Ong, S.-Q., and Jaal, Z. (2015). Investigation of mosquito oviposition pheromone as lethal lure for the control of Aedes aegypti (L.) (Diptera: Culicidae). Parasit. Vectors 8, 28. doi: 10.1186/s13071-015-0639-2

Ooi, E. E., Goh, K. T., and Gubler, D. J. (2006). Dengue prevention and 35 years of vector control in Singapore. Emerging Infect. Dis. 12, 887-893. doi: 10.3201/eid1206.051210

Pan American Health Organization (2014). (PAHO). Technical Note on Transgenic Mosquitoes Engineered for Aedes Aegypti Control. Washington, DC. Available online at: http://www2.paho.org/hq/index.php?option=com_docman\&task= doc_view\&gid=28197\&Itemid=1994

Pérez-Guerra, C. L., Zielinski-Gutierrez, E., Vargas-Torres, D., and Clark, G. G. (2009). Community beliefs and practices about dengue in Puerto Rico. Rev. Panam. Salud Publica 25, 218-226. doi: 10.1590/S1020-49892009000300005

Perng, G. C., Lei, H.-Y., Lin, Y.-S., and Chokephaibulkit, K. (2011). Dengue vaccines: challenge and confrontation. World J. Vaccin. 1, 109-130. doi: 10.4236/wjv.2011.14012

Pierre, D. Y., Okechukwu, E. C., and Nchiwan, N. E. (2014). Larvicidal and phytochemical properties of Callistemon rigidus $\mathrm{R}$. Br. (Myrtaceae) leaf solvent extracts against three vector mosquitoes. J. Vector Borne Dis. 51, 216-223.

Qiao, M., Shaw, D., Forrat, R., Wartel-Tram, A., and Lang, J. (2011). Priming effect of dengue and yellow fever vaccination on the immunogenicity, infectivity, and safety of a tetravalent dengue vaccine in humans. Am. J. Trop. Med. Hyg. 85, 724-731. doi: 10.4269/ajtmh.2011.10-0436

Ramkumar, G., Karthi, S., Muthusamy, R., Natarajan, D., and Shivakumar, M. S. (2015). Adulticidal and smoke toxicity of Cipadessa baccifera (Roth) plant extracts against Anopheles stephensi, Aedes aegypti, and Culex quinquefasciatus. Parasitol. Res. 114, 167-173. doi: 10.1007/s00436-014-4173-5

Reis-Castro, L. (2012). Genetically modified insects as a public health tool: discussing the different bio-objectification within genetic strategies. Croat. Med. J. 53, 635-638. doi: 10.3325/cmj.2012.53.635

Sabchareon, A., Wallace, D., Sirivichayakul, C., Limkittikul, K., Chanthavanich, P., Suvannadabba, S., et al. (2012). Protective efficacy of the recombinant, live-attenuated, CYD tetravalent dengue vaccine in Thai schoolchildren: a randomised, controlled phase $2 \mathrm{~b}$ trial. Lancet 380, 1559-1567. doi: 10.1016/S0140-6736(12)61428-7

Saldaña, M. A., Hegde, S., and Hughes, G. L. (2017). Microbial control of arthropod-borne disease. Mem. Inst. Oswaldo. Cruz. 112, 1-13. doi: 10.1590/0074-02760160373

Sandrasegaran, A. (2016). Primary prevention of dengue: a comparison between the problems and prospects of the most promising vector control and vaccination approaches. Aust. Med. Stud. J. 7, 51-54.

Sarathy, V. V., White, M., Li, L., Gorder, S. R., Pyles, R. B., Campbell, G. A., et al. (2015). A lethal murine infection model for dengue virus 3 in AG129 mice deficient in type I and II interferon receptors leads to systemic disease. J. Virol. 89, 1254-1266. doi: 10.1128/JVI.01320-14

Scarpino, S. V., Meyers, L. A., and Johansson, M. A. (2017). Design Strategies for efficient arbovirus surveillance. Emerging Infect. Dis. 23, 642-644. doi: 10.3201/eid2304.160944

Seng, C. M., Setha, T., Nealon, J., Socheat, D., Chantha, N., and Nathan, M. B. (2008). Community-based use of the larvivorous fish Poecilia reticulata to control the dengue vector Aedes aegypti in domestic water storage containers in rural Cambodia. J. Vector Ecol. 33, 139-144. doi: 10.3376/10811710(2008)33[139:CUOTLF]2.0.CO;2

Shriram, A. N., Sugunan, A. P., Manimunda, S. P., and Vijayachari, P. (2009). Community-centred approach for the control of Aedes spp. in a peri-urban zone in the Andaman and Nicobar Islands using temephos. Natl. Med. J. India $22,116-20$. 
Simmons, C. P., Farrar, J. J., Nguyen, V. C., and Wills, B. (2012). Dengue. N. Engl. J. Med. 366, 1423-1432. doi: 10.1056/NEJMra1110265

Sin Leo, Y., Wilder-Smith, A., Archuleta, S., Shek, L. P., Chong, C. Y., Nam Leong, $\mathrm{H}$., et al. (2012). Immunogenicity and safety of recombinant tetravalent dengue vaccine (CYD-TDV) in individuals aged $2-45$ years. Hum. Vaccin. Immunother. 8, 1259-1271. doi: 10.4161/hv.21224

Swaminathan, S., and Khanna, N. (2010). Dengue vaccine - current progress and challenges. Curr. Sci. 98, 369-378.

Tapia-Conyer, R., Méndez-Galván, J., and Burciaga-Zú-iga, P. (2012). Community participation in the prevention and control of dengue: the patio limpio strategy in Mexico. Paediatr. Int. Child Health 32(Suppl. 1), 10-13. doi: 10.1179/2046904712Z.00000000047

Thomas, S. J. (2013). Dengue human infection model. Hum. Vaccin. Immunother. 9, 1587-1590. doi: 10.4161/hv.24188

Vanlerberghe, V., Toledo, M. E., Rodríguez, M., Gómez, D., Baly, A., Benítez, J. R., et al. (2010). Community involvement in dengue vector control: cluster randomised trial. MEDICC Rev. 12, 41-47. doi: 10.1136/bm j.b1959

Villar, L. Á., Rivera-Medina, D. M., Arredondo-García, J. L., Boaz, M., StarrSpires, L., Thakur, M., et al. (2013). Safety and immunogenicity of a recombinant tetravalent dengue vaccine in 9-16 year olds a randomized, controlled, phase ii trial in Latin America. Pediatr. Infect. Dis. J. 32, 1102-1109. doi: 10.1097/INF.0b013e31829b8022

Villar, L., Dayan, G. H., Arredondo-García, J. L., Rivera-Medina, D. M., Cunha, R., Deseda, C., et al. (2015). Efficacy of a Tetravalent dengue vaccine in children in Latin America. N. Engl. J. Med. 372, 113-123. doi: 10.1056/NEJMoa1411037

Warbanski, M. L., Marques, P., Frauendorf, T. C., Phillip, D. A. T., and El-Sabaawi, R. W. (2017). Implications of guppy (Poecilia reticulata) life-history phenotype for mosquito control. Ecol. Evol. 7, 1-11. doi: 10.1002/ece3.2666
WHO (2012). Global Strategy for Dengue Prevention and Control 2012-2020. Geneva: World Health Organization.

Wilder-Smith, A., Renhorn, K. E., Tissera, H., Bakar, S. A., Alphey, L., Kittayapong, P., et al. (2012). Dengue tools: innovative tools and strategies for the surveillance and control of dengue. Glob. Health Action 5. doi: 10.3402/gha.v5i0.17273

Wilke, A. B. B., and Marrelli, M. T. (2015). Paratransgenesis: a promising new strategy for mosquito vector control. Parasit. Vectors 8, 342. doi: 10.1186/s13071-015-0959-2

Wong, J., Stoddard, S. T., Astete, H., Morrison, A. C., and Scott, T. W. (2011). Oviposition site selection by the dengue vector Aedes aegypti and its implications for dengue control. PLoS Negl. Trop. Dis. 5:e1015. doi: 10.1371/journal.pntd.0001015

Yakob, L., Funk, S., Camacho, A., Brady, O., and Edmunds, W. J. (2017). Aedes aegypti control through modernized, integrated vector management. PLoS Curr. 9:8747. doi: 10.1371/currents.outbreaks.45deb8e03a438c4d088afb4fafae8747

Conflict of Interest Statement: The authors declare that the research was conducted in the absence of any commercial or financial relationships that could be construed as a potential conflict of interest.

Copyright $\odot 2017$ Rather, Parray, Lone, Paek, Lim, Bajpai and Park. This is an open-access article distributed under the terms of the Creative Commons Attribution License (CC BY). The use, distribution or reproduction in other forums is permitted, provided the original author(s) or licensor are credited and that the original publication in this journal is cited, in accordance with accepted academic practice. No use, distribution or reproduction is permitted which does not comply with these terms. 